\title{
Georgia en el sistema político estadunidense contemporáneo: evolución en el Sur tradicional
}

\author{
ERNESTO DOMÍNGUEZ LóPEZ*
}

\begin{abstract}
RESUMEN
En este artículo se propone un estudio de la evolución de la participación del estado de Georgia en los procesos electorales en Estados Unidos, a partir de la posguerra y hasta 2012. Para ello se aplicaron métodos estadísticos y comparativos, utilizando la información obtenida de los sitios estadísticos oficiales, sitios independientes y observaciones sobre el terreno. Se determinó que la evolución de los subprocesos presidenciales y congresionales ha sido diacrónica. Se observó una tendencia a los reacomodos de fuerzas, apreciable en el comportamiento de los indicadores electorales, a tono con la variación de la composición étnica de la población del estado.
\end{abstract}

Palabras clave: Estados Unidos, Georgia, elecciones, sistema político, composición étnica.

\section{ABSTRACT}

This article studies the evolution of Georgia's participation in U.S. elections from the end of World War II to 2012. The author uses statistic and comparative methods, using information from both official and independent sources, plus field observations. He determined that the evolution of the presidential and congressional sub-processes has been diachronic and observed a tendency to readjust forces visible in the behavior of electoral indicators and that jibes with the variation in the ethnic composition of the state's inhabitants.

Key words: United States, Georgia, elections, political system, ethnic composition.

* Centro de Estudios Hemisféricos y sobre Estados Unidos (CEHSEU), Universidad de La Habana, <ernestodl@ rect.uh.cu>. 
El sistema político de Estados Unidos es referente obligado para los ensayos en varios países y diferentes momentos históricos y, como tal, un objeto de estudios recurrente y difícilmente agotable en un futuro previsible. Entre las peculiaridades más significativas y de más larga data en la composición y funcionamiento de aquel país, se encuentra la diferenciación entre Norte y Sur. Las dos secciones, como se las llama en la historiografía y la politología estadunidense, tuvieron procesos formativos (en gran medida separados), que generaron estructuras sociales, económicas y de pensamiento muy distintas.

El factor más explícito de esa fractura fue durante mucho tiempo el problema de la esclavitud, base de la estructura productiva del Sur tradicional, pero abolida tempranamente en el Norte (Mason, 2006; Genovese, 1989; Foner, 2011). La historia contemporánea está llena de procesos políticos en los que la distribución territorial de las preferencias e intereses políticos de los ciudadanos estadunidenses ha estado muy claramente definida. En términos geográficos, la polarización permite trazar una frontera a lo largo de la línea que separó los estados esclavistas de los "libres" a partir del Compromiso de Missouri de 1820.

Con esas peculiaridades como antecedente, el estudio del desarrollo de las relaciones políticas dentro de Estados Unidos tiene necesariamente que considerar esas diferencias seccionales. En la actualidad se asocia el Sur con el Partido Republicano y el Noreste (el antiguo Norte) con los demócratas, pues tienen allí sus bastiones más importantes, como se aprecia en los resultados electorales; sin embargo, ésta es una realidad viva, resultado de una serie de interacciones y condiciones que cambian en el tiempo, a ritmos diferentes.

En este trabajo se propone una aproximación al estado de Georgia. Como parte del Sur tradicional, las construcciones identitarias propias de la región se encuentran presentes con gran fuerza en la conformación del ordenamiento social georgiano actual, y, sin embargo, no todo es tan simple como parece. Una observación algo más detallada descubre algunos matices interesantes. Se propone esta aproximación a ese territorio específico, pues por su historia y características puede considerarse una muestra representativa de ese Sur, y ahí se identifican algunas de las tendencias estructurales presentes en toda la región meridional.

Teniendo esto en cuenta, el objetivo trazado es explicar la evolución del papel de Georgia en el sistema político federal estadunidense, particularmente en los procesos electorales, desde mediados del siglo xx. A partir de ahí, me propuse identificar las tendencias más importantes de ese desarrollo, y relacionarlas con los factores demográficos, entendidos como condicionantes del comportamiento del electorado estatal.

Durante la investigación se utilizaron métodos estadísticos, comparativos e histórico-lógicos para sistematizar y sintetizar la información recogida. Se tuvo, además, 
la oportunidad de realizar observaciones directas y entrevistas relacionadas con el proceso electoral de 2012, lo cual enriquece considerablemente los resultados.

En el texto se utilizó intensivamente la información proporcionada por varias fuentes oficiales, como la Oficina del Censo de Estados Unidos. Otras fuentes no son oficiales, pero sí fidedignas. Los criterios expresados aquí son resultado del estudio de esos datos y de observaciones del autor sobre el terreno, que incluyen la recepción por el público de los mensajes de campaña y actitudes diversas, comprobadas también mediante el diálogo con especialistas y ciudadanos comunes.

\section{LAS ELECCIONES Y EL COLEGIO ELECTORAL}

El sistema electoral estadunidense está sujeto a la condición presidencialista de la república, los fundamentos de su federalismo y el carácter indirecto de la elección presidencial. El jefe de Estado se elige por separado en elecciones específicas, donde los estados desempeñan un papel fundamental, por medio de los llamados colegios electorales. Para la rama legislativa, el modelo es de mayoría por distritos. Ello significa que el papel principal dentro de la dramaturgia política lo representan las figuras de los candidatos, con su imagen y su acceso a los medios, así como a las distintas formas de promoción. A esto debemos sumar la relativa debilidad estructural de las formaciones partidistas, las cuales actúan más como foros de coordinación entre grupos y corrientes políticas e ideológicas, que como organizaciones coherentes (Chhibber y Kollman, 2004).

Por tanto, dentro del proceso electoral a nivel federal existen tres subprocesos interconectados, cuyos resultados definen qué figuras ocupan los puestos elegibles: elecciones presidenciales, para la Cámara de Representantes y para el Senado. En el segundo se renueva un tercio de los mandatos cada dos años, mientras que la Cámara Baja se presenta a elecciones en su totalidad cada vez. Los tres presentan rasgos comunes que emanan de los fundamentos organizacionales del sistema político como un todo, particularmente, la competencia entre candidatos individuales, lo cual implica la búsqueda de una legitimidad personal basada en el carisma, aunque el sistema en su conjunto posee una fuerte legitimidad legal. Todas las tipologías propuestas por Max Weber (1971: 170-241) se hallan en este sistema, pero considero que se articulan en torno a estas dos. Esto implica entender los pilares de la legitimidad como una combinación de factores con múltiples rasgos, incluyendo los identificados como subjetivos y objetivos. Dentro de los marcos de un muy consolidado bipartidismo, esto se expresa en la oscilación entre los dos extremos de ese dipolo. 
Una de las especificidades más significativas del sistema electoral estadunidense es la existencia del colegio electoral: un grupo de electores compromisarios seleccionados en cada estado, cuyos sufragios son los que definen el resultado de la votación por la fórmula presidente-vicepresidente. El funcionamiento de esta institución y el procedimiento electoral a nivel federal están regulados por la sección 1 del artículo II de la Constitución, parcialmente modificado por la Decimosegunda Enmienda (de 1804). Están también recogidos y ampliados en el capítulo 1 del Título 3 del U.S. Code (2011). La otra modificación del proceso se introdujo con la Vigesimotercera Enmienda, aprobada el 3 de abril de 1961 (Hall, ed., 1992: ix-xxvi), en la cual se establece la creación del colegio electoral del Distrito Federal de Columbia, sede del gobierno federal.

Según estas disposiciones, cada entidad cuenta con un colegio, cuya membresía equivale al número de senadores y representantes que tenga en ese momento. Washington, D. C. cuenta con un número igual al que tendría si fuera un estado, con la salvedad de que el número no puede ser superior al del estado que menos tenga. Esas cifras se reajustan según los resultados que arrojan los censos decenales, sobre cuya base se redistribuyen los cuatrocientos treinta y cinco puestos de la Cámara de Representantes, de acuerdo con el principio de al menos un representante por estado y una fórmula de prioridades para la ubicación de los escaños a partir del número cincuenta y uno, aprobada por el propio Congreso. La definición de los distritos electorales es resultado de otro proceso, que históricamente ha priorizado el principio espacial y no el poblacional, lo cual favorece a las áreas de menor densidad poblacional y, por tanto, otorga cuotas considerables a las zonas rurales, las cuales quedan sobrerrepresentadas en el Legislativo federal (U.S. Census Bureau, 2010a).

Como se aprecia claramente, el modo de elegir al jefe de Estado y su sustituto constitucional está organizado según un modelo de más de dos siglos de antigüedad. Dicho modelo establecía una votación indirecta, en la cual el voto popular, inicialmente reducido, sólo era importante en la selección de los compromisarios, quienes poseían capacidad de decisión. En la práctica, esto último ha variado en el tiempo, hasta convertirse actualmente en un paso meramente formal, pues el resultado final es conocido desde que finalizan las elecciones en el estado, aunque queden espacios para algunas sorpresas.

¿Cuál es el sentido, entonces, de mantener esa estructura? En ello confluyen varios factores: el primero proviene de su introducción, en los orígenes mismos, y es la protección de la relación de poder en la sociedad. La Convención de Filadelfia, convocada en 1787, era básicamente una reunión de comerciantes, hombres de negocios, plantadores, abogados, presidentes de colleges, en total cincuenta y cinco delegados de doce de los trece estados originales (excepto Rhode Island), representantes de la elite de la sociedad estadunidense. En esa cifra se contaban figuras como Alexander 
Hamilton, James Madison y James Wilson; mientras se encontraban ausentes por diversos motivos otros como Thomas Jefferson, John Adams, John Jay y Samuel Adams (Foner, 2011: 267-271; Morrison, Commager y Leuchtenburg, 1987: 155-169; Franco, Fernández y Lorenzo, comps., 1996: 67-94). Los fundadores de la federación eran conscientes de la existencia de múltiples divisiones en la sociedad, fragmentos que eran resultado de las diversas condiciones de los individuos, que ellos asociaban con la propiedad.

En su criterio, el gobierno federal debía coordinar a estos grupos en pro del bien mayor, para lo cual tenía que estar en manos de los más capacitados, ergo, debía ser controlado por una clase o sistema de clases dirigentes (Hamilton, Madison y Jay, 1961). Este pensamiento se asocia directamente con la formación de lo que Mills (1957) llamó "elite de poder".

En la actualidad, si bien el papel individual de los compromisarios prácticamente ha desaparecido, su existencia introduce una distorsión del voto popular que, de hecho, cierra el paso a posibles propuestas alternativas que se presentaran fuera de los partidos fundamentales del sistema. Esto reviste importancia adicional si observamos la ampliación paulatina del derecho al voto que introdujeron las enmiendas Decimocuarta (1868), Decimoquinta (1870), Decimonovena (1920) y Vigesimasexta (1971) (Hall, ed., 1992: ix-xxvi), unidas a las tendencias demográficas, como el crecimiento sostenido de la población considerada hispana y asiática, además de la considerable población negra. Lo cierto es que los factores que incidieron en la formación original del modelo federal estadunidense y, por tanto, de la definición de sus marcos legales, influyen hasta hoy en la estructura y funcionamiento del sistema político.

Uno de los factores de este desarrollo ha sido la extensión del principio de winner takes all, es decir, que los representantes del partido que postula al candidato con la mayor parte de los votos emitidos en un estado, aunque sea por un margen muy estrecho, recibe la totalidad de los puestos del colegio. Las excepciones en este punto son Nebraska y Maine. En el caso de Nebraska, por ejemplo, se otorga un voto electoral al ganador de cada uno de sus distritos congresionales y dos al ganador general del estado. Por supuesto, la importancia de estos casos es mínima, pues en la distribución actual cuentan con apenas cinco y cuatro votos, respectivamente, además de que sólo ha sucedido una vez, cuando Barack Obama ganó uno de los votos de Nebraska. Esto es posible porque, según lo establecido por la Constitución, cada estado define cómo se realiza la elección de los compromisarios.

Para comprender un poco mejor este aspecto, cabe considerar otra de las características básicas de Estados Unidos: su condición de federación, particularmente, el problema de la soberanía. En efecto, en una federación moderna existen, de derecho, dos soberanías: la del pueblo (entendido como el conjunto de los ciudadanos de ese 
Estado) y la de los sujetos de aquélla. En el caso estadunidense, estaríamos hablando de la soberanía del pueblo y de cada uno de los cincuenta estados.

Esta doble soberanía está expresada en el bicameralismo, donde la Cámara Baja representa a los ciudadanos, mientras que la Cámara Alta, a los estados. Por eso, en la primera el número de representantes por estado se ajusta periódicamente, mientras que la segunda permanece fija. Es interesante que hasta la aprobación de la Decimoséptima Enmienda (en 1913), los senadores fueran elegidos por las asambleas legislativas estatales, y sólo después de esa fecha pasaron a ser elegidos por el pueblo de los estados (Hall, ed., 1992: ix-xxvi).

En una medida apreciable, el sistema electoral recoge esa condición, al ponderar el voto por estados, dentro de los cuales es que se produce la votación popular. Dicho en otras palabras, no es una elección, sino cincuenta y uno (contando el Distrito Federal de Columbia), cada una de las cuales da un único resultado, mediado por las decisiones de los compromisarios, y la suma de todas ellas es la que define el ganador final.

Luego, que se mantenga el colegio electoral responde al menos a tres causas visibles: 1) el sostenimiento de un mecanismo de control del sistema por las elites, aunque dicho de manera tan llana pareciera haber perdido eficacia; 2) la ponderación del voto por estados, de acuerdo con la histórica exigencia de éstos de mantener grandes cuotas de autonomía y 3) no debemos olvidar la continuidad de una tradición que incluye la conservación de una Constitución a todas luces anticuada. Además, esta estructura permite la existencia de elites locales, con capacidad para influir sobre el funcionamiento del Estado federal, en la medida en que controlan notables cuotas de poder político.

\section{LA HISTORIA DE UN SOLID STATE}

Los distintos sujetos federados en los que se desarrolla la elección presidencial en particular muestran comportamientos muy diferentes. La mayoría tienen claramente definido, desde etapas tempranas del proceso, por qué candidato se inclinarán, se los considera sólidos (solid states) y, por tanto, son menores los recursos y esfuerzos que les dedican los competidores. Existe un número más reducido en los que ninguno de los contendientes tiene una clara ventaja en la intención de voto de los electores registrados que se considere decisiva y, por ende, están abiertos para cualquiera. Éstos son los que deciden y son los que atraen el grueso de la acción de las campañas. Dichos estados reciben varios nombres: estados campos de batalla (battleground states), estados púrpuras (purple states) o estados pendulares (swing states). Actualmente se considera que Georgia está en la primera de estas categorías, favorable a los republicanos. 
La historia política de Estados Unidos está marcada por una serie de realineamientos de las fuerzas políticas en lo referente a sus plataformas programáticas y sus discursos electorales, acompañados por la redistribución territorial de sus bases sociales. Ello es el resultado de la combinación de múltiples procesos, como los cambios en las correlaciones de fuerzas entre los intereses de los sectores de las elites vinculados con cada una de las formaciones, y entre las corrientes y grupos dentro de éstas, así como en la composición de los electorados. Un número importante de autores les ha reconocido un carácter cíclico, el cual ha llegado a considerarse como uno de los componentes fundamentales de la historia estadunidense (Schlesinger, 1990: 41-64; Burnham, 1970).

Las elecciones presidenciales en Georgia fueron ganadas ininterrumpidamente y durante largo tiempo por los demócratas, quienes se impusieron en todas a partir de 1852. Incluso durante los años de la reconstrucción, el electorado georgiano se inclinó por el Partido Demócrata. La implementación del New Deal (nuevo orden) y más tarde la actuación de las sucesivas administraciones de Franklin D. Roosevelt durante la segunda guerra mundial contribuyeron a mantener un alto nivel de apoyo, que se tradujo en votaciones constantemente por encima del 80 por ciento en los comicios que siguieron (The American Presidency Project, 2012). Los resultados de Roosevelt constituyen las cotas más altas alcanzadas por cualquier candidato presidencial en Georgia y compiten favorablemente con las cifras más elevadas que puedan encontrarse en cualquier otro territorio.

El cuadro 1 muestra los resultados correspondientes a la segunda mitad del siglo xx y principios del xxi. Lo que se evidencia es que en las elecciones de 1948 a 1960 los demócratas mantuvieron el control del colegio electoral con márgenes amplios, pero también se observa claramente una paulatina reducción de estos últimos. Es un síntoma de que se estaban produciendo cambios en la correlación de fuerzas entre los partidos en este territorio, una lenta redistribución de las bases electorales que reflejaba los principios de un trasvase continuo de votos hacia los republicanos. Esa situación alcanzó un punto crítico en 1964.

Aquí incidieron varios factores, los cuales habría que estudiar detenidamente. Ése fue el año de la aprobación de la Civil Rights Act, la cual cortó radicalmente los vínculos históricos del Partido Demócrata con los sectores tradicionalistas y racistas del Sur (Hasday, 2007); a su vez, fue un pivote en la construcción de fuertes lazos entre esa formación y las diversas minorías étnicas que ya existían o que se fueron constituyendo como núcleos importantes y marginados de la población estadunidense. La combinación de este acontecimiento con los cambios estructurales que se produjeron desde los años treinta catalizó el proceso de reorganización del sistema político en todos sus aspectos. A ello hay que sumar los efectos de la aplicación de la Southern 
Strategy republicana, que se apoyaba en el descontento de los conservadores del Sur para atraer esa masa de votos hacia los republicanos, con un discurso que retomaba en su centro el tema de los derechos de los estados y las libertades individuales (Black y Black, 2002; Schafer y Johnston, 2006).

\begin{tabular}{|c|c|c|c|}
\hline \multicolumn{4}{|c|}{$\begin{array}{c}\text { Cuadro } 1 \\
\text { RESULTADOS DE LAS ELECCIONES PRESIDENCIALES EN GEORGIA, } \\
\text { DESPUÉS DE LA SEGUNDA GUERRA MUNDIAL }\end{array}$} \\
\hline Año & Ganador del estado & $\begin{array}{l}\text { Ganador } \\
\text { general }\end{array}$ & $\begin{array}{l}\text { Diferencia en el estado } \\
\text { (porcentaje del total } \\
\text { de votantes) }\end{array}$ \\
\hline 1948 & Demócrata (Truman) & Truman & $169511(40.5)$ \\
\hline 1952 & Demócrata (Stevenson) & Eisenhower (R) & $257862(39.4)$ \\
\hline 1956 & Demócrata (Stevenson) & Eisenhower & $221910(33.1)$ \\
\hline 1960 & Demócrata (Kennedy) & Kennedy & $184166(25.1)$ \\
\hline 1964 & Republicano (Goldwater) & Johnson (D) & $94028 \quad(8.2)$ \\
\hline 1968 & Independiente (Wallace) & Nixon & $155439(12.4)$ \\
\hline 1972 & Republicano (Nixon) & Nixon & $591967(50.4)$ \\
\hline 1976 & Demócrata (Carter) & Carter & $495666(33.7)$ \\
\hline 1980 & Demócrata (Carter) & Reagan (R) & $236565(14.8)$ \\
\hline 1984 & Republicano (Reagan) & Reagan & $362094(20.4)$ \\
\hline 1988 & Republicano (Bush) & Bush & 366539 (20.3) \\
\hline 1992 & Demócrata (Clinton) & Clinton (D) & $13714 \quad(0.6)$ \\
\hline 1996 & Republicano (Dole) & Clinton & $26994 \quad(1.2)$ \\
\hline 2000 & Republicano (Bush) & Bush & $303490(11.7)$ \\
\hline 2004 & Republicano (Bush) & Bush & $548105(16.6)$ \\
\hline 2008 & Republicano (McCain) & Obama (D) & $204607 \quad(5.2)$ \\
\hline 2012 & Republicano (Romney) & Obama & $308460 \quad(8.0)$ \\
\hline
\end{tabular}

El camino de Georgia hacia el lado republicano fue relativamente largo y complicado. Teniendo en cuenta los resultados electorales, los años sesenta se ven como un periodo transicional, si atendemos a que la victoria (por una diferencia relativamente reducida) del muy radical republicano Barry Goldwater en 1964 fue seguida por la del "tercer candidato" George Wallace, quien aplicó su propia Southern Strategy. Éste era un antiguo demócrata, quien condujo una campaña y en general presentó una propuesta que combinaba el populismo de corte sureño, con posiciones 
prosegregacionistas y los llamados a la ley y el orden. La victoria, muy amplia, de Richard Nixon en 1972 habría sido la culminación del proceso de realineamiento de las fuerzas políticas en el estado, pero los comicios que siguieron en los setenta produjeron un retroceso en ese camino con las cómodas victorias locales de Jimmy Carter, aupado en 1976 por los efectos del escándalo Watergate (Foner, 2011: 1092-1093).

Por tanto, en relación con las elecciones presidenciales, en los años cuarenta, cincuenta, sesenta y setenta se distinguen fácilmente dos periodos: el que abarcó las dos primeras décadas fue la etapa final de la hegemonía demócrata en el Peach State (Georgia); el segundo es un proceso transicional, largo y complejo, extendido además por la conocida crisis política desatada por el escándalo Watergate. En este último caso, incidió también que James Carter es oriundo de Georgia, por lo que en esas votaciones actuaron también factores no específicamente políticos, algo que identificamos como voto regionalista, cuyos efectos se presentan en las distintas contiendas electorales estadunidenses, con fuerza variable, por supuesto.

Si observamos la gráfica 1, se evidencia que esos procesos a los que nos referimos se expresan también en el comportamiento de las diferencias obtenidas por los ganadores. En los cuatro primeros comicios, los márgenes se sostuvieron por encima del 25 por ciento, aunque en descenso. En 1964, se produjo un mínimo local, seguido por márgenes mayores hasta el máximo global de 1972. A partir de ahí se registraron descensos muy notables, aunque todavía en niveles muy elevados.

\section{Gráfica 1}

DIFERENCIA ENTRE LOS PRINCIPALES CANDIDATOS

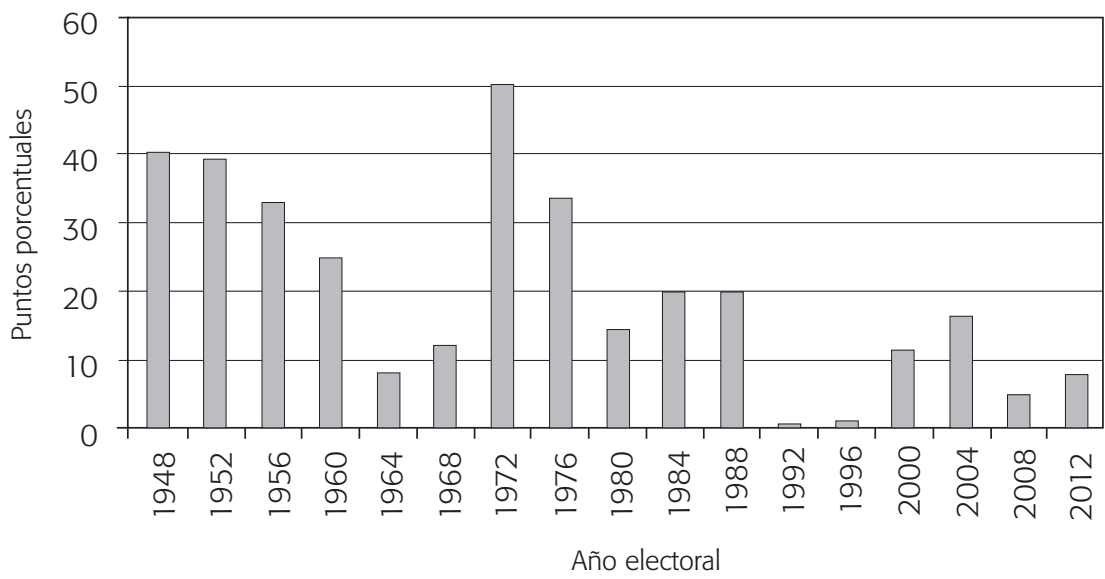

Fuente: Elaboración propia con información de The American Presidency Project (2012). 
A partir de las elecciones de 1984, desarrolladas bajo los efectos ya dominantes de la llamada revolución conservadora y de la exitosa proyección pública de Ronald Reagan, el control del colegio electoral se desplazó hacia el Partido Republicano. Con la excepción de la apretada victoria de William Clinton en 1992, los candidatos republicanos se han impuesto en ese estado desde entonces. El triunfo de Clinton tiene algunas peculiaridades, pues es natural de Arkansas, con lo cual pudo atraer determinadas manifestaciones de las identidades seccionales, se produjo en medio de una recesión que golpeó al país y se convirtió en el centro de su discurso electoral. Todavía se recuerda que la frase "It's the economy, stupid!", aplicada al entonces presidente George H. W. Bush, marcó el eje fundamental de la campaña política, el ingrediente clave de su éxito.

Además de ello, cabe considerar otros aspectos para comprender ese resultado. Por una parte, no se puede omitir el impacto de la personalidad de Clinton, quien se mostró como un gran comunicador y un hábil político, capaz de atraer a múltiples sectores, aprovechando además su condición de blanco, anglosajón y protestante de clase media, es decir, un representante del arquetipo del ciudadano estadunidense. Por otra, la política que promovió y ejecutó el primero senador y después presidente en el ejercicio de sus cargos buscaba un reequilibrio de las posiciones ideológicas, políticas y teóricas, en busca de consolidar un nuevo consenso. Fue un demócrata muy moderado, influido por las corrientes neoliberales y neoconservadoras, que en su práctica política intentó la combinación de algunos componentes del llamado liberalismo estadunidense, con fuertes núcleos consolidados con la revolución conservadora. En ese sentido, fue reconocido como una de las figuras centrales de la llamada Tercera Vía, y como tal cercano a Tony Blair y Gerhard Schröder (Giddens, 2003).

Posteriormente, volvieron los triunfos republicanos, con Robert Dole por delante del propio Clinton en 1996, George W. Bush, John McCain y Mitt Romney. Por tanto, se caracteriza la etapa 1984-2012 como un periodo de hegemonía republicana, tanto por sus victorias electorales como por las peculiaridades del único demócrata vencedor en esos años. Pero al superponer estos datos con los de la gráfica 1, contamos una historia algo diferente. En 1984 y 1988, Reagan y Bush se habían impuesto con más del 20 por ciento de diferencia, pero posteriormente no se observaron cifras parecidas. En 1992, se registró un mínimo histórico de 0.6 puntos y cuatro de los seis resultados han estado por debajo de la barrera de los diez puntos. Los dos ejercicios que la superaron fueron los dos triunfos de Bush Jr., el más radical de todos los candidatos republicanos del periodo, en un contexto de mucha polarización. En la gráfica apreciamos que el comportamiento de este indicador se parece más al del periodo transicional de los sesenta-setenta que a la hegemonía demócrata precedente. 
Con esto no quiero decir que los dos periodos sean iguales. Lo que apunto es que el predominio republicano se ha dado en condiciones de equilibrio relativo en el ámbito de la elección presidencial. Por tanto, aunque en 2012, por ejemplo, Georgia no fue vista nunca como un swing state y un triunfo demócrata se considerara siempre muy improbable, no se trata de un escenario claramente asegurado a largo plazo para el Partido Republicano, en el cual los demócratas tendrían posibilidades si se produjeran algunos cambios significativos en el sistema de condicionantes dentro del cual se desarrollan esos procesos.

Por otra parte, el peso del Peach State en el sistema político estadunidense, y particularmente en el colegio electoral, ha tenido una evolución también lenta. En primer lugar, la proporción que representan los votantes efectivos georgianos ha tendido a aumentar desde el fin de la segunda guerra mundial. En la gráfica 2 se aprecia una tendencia lineal ascendente, aunque el rango de valores es relativamente bajo, si lo comparamos con los correspondientes a estados como Texas y Florida -el 6.5 y el 6.9 por ciento en 2012, respectivamente (The American Presidency Project, 2012)-. Pero en cualquier caso hay una tendencia sostenida al crecimiento.

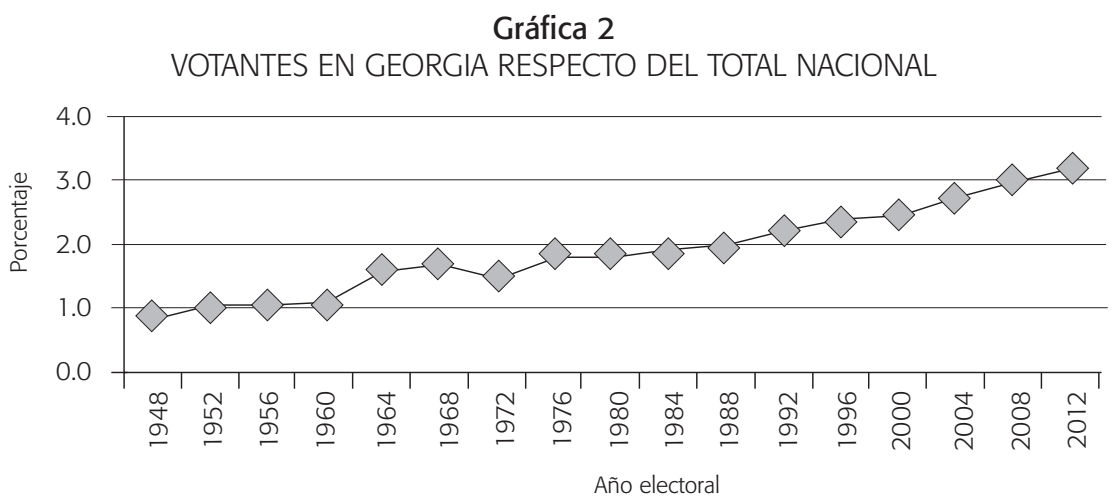

Fuente: Elaboración propia con datos de The American Presidency Project (2012).

Sin embargo, esto no se traduce en una tendencia similar en la importancia del colegio electoral en la elección presidencial, como nos muestra la gráfica 3. Por supuesto, no hay una relación inmediata entre las dos variables, pues la primera depende de factores como los índices de participación local y nacional, mientras que la segunda es resultado de la redistribución de los puestos en la Cámara, a partir de las variaciones en las poblaciones de los estados. Aun así, se esperaría una cierta semejanza entre los comportamientos. Los datos en las gráficas muestran otra cosa. Durante décadas, el número de electores compromisarios se mantuvo estancado, con un descenso incluso 
a raíz del censo de 1960. Sólo después del censo de 1990 se observa un crecimiento, con un número significativo, aunque no grande, de nuevos compromisarios.

\section{Gráfica 3}

PESO RELATIVO DEL COLEGIO ELECTORAL DE GEORGIA

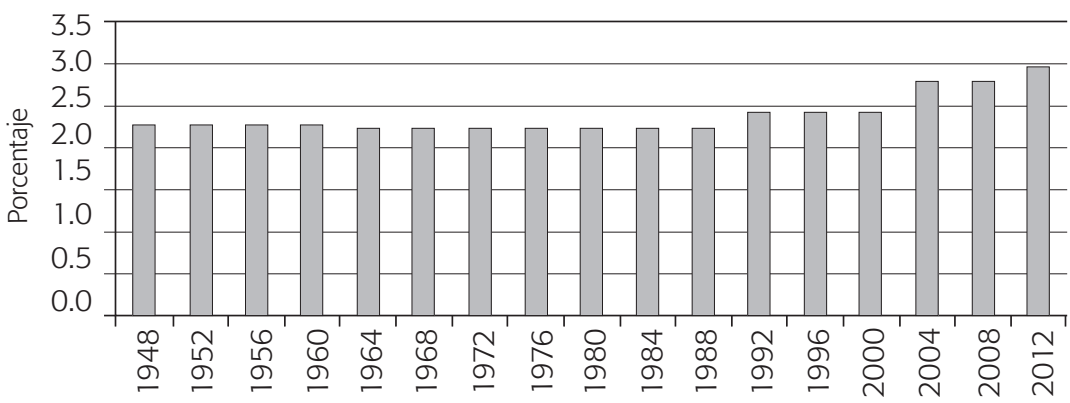

Elecciones

Fuente: Elaboración propia con datos de The American Presidency Project (2012).

Las redistribuciones de 1990 a 2010 hicieron a Georgia ganar cuatro votos y, por tanto, influir algo más en el resultado final, pero todavía lejos del primer orden. En aras de la precisión, hablamos de un estado grande en términos poblacionales y electorales. Por las dimensiones de su colegio, ocupa el octavo-noveno puesto, igualado con Michigan. Estaría en un cuarto orden, si se considera que California se encuentra en el primero, con sus cincuenta y cinco compromisarios, Texas en el segundo con sus treinta y ocho, Florida y Nueva York en el tercero con veintinueve, y en el cuarto colocaríamos una serie de territorios en el rango de quince a veinte: Pennsylvania, Illinois, Ohio, Michigan, Georgia y Carolina del Norte.

Hay algunos factores que aún se considerarían para comprender mejor el comportamiento electoral de este estado y sus perspectivas. Por ejemplo, aquí funciona una red de simpatizantes y activistas demócratas que tiene una nada desdeñable capacidad movilizadora. Centrada naturalmente en Atlanta, se integran en ella intelectuales, profesionales de distintos tipos, jóvenes de diversas extracciones y algunos miembros de minorías étnicas. La fractura zona urbana-zona rural es muy evidente en este caso, en el que la capital estatal es considerada una mancha azul en un mapa rojo. En la misma medida en que ese núcleo urbano se ha ido consolidando como un importante centro de actividad político-administrativa y académica, se ha configurado con más fuerza esa situación. 
Esto también se relaciona con la presencia de un número considerable de personas de otros orígenes en esos espacios, particularmente entre el claustro y el estudiantado universitario. Se observó, durante la campaña, un amplio despliegue de carteles promocionales, actividades políticas de diversa índole y discusiones informales a favor de la candidatura de Obama, tratando de promover, además, otras propuestas del Partido Demócrata. Fue muy llamativo cómo numerosos grupos de personas de disímiles posiciones sociales celebraron la victoria de Obama en diferentes escenarios. Por citar un ejemplo, este autor estuvo en contacto con al menos cuatro electoral parties, celebradas simultáneamente en espacios públicos y privados, todas en apoyo del presidente reelecto.

En cambio, el resto del estado, donde predominan zonas rurales y áreas metro y micropolitanas de menor importancia y cosmopolitismo, el activismo demócrata era prácticamente nulo. Por el contrario, se hallaban prácticamente cubiertas de promociones de las candidaturas republicanas, mezcladas con discursos e imágenes dirigidos a las distintas versiones del nativismo más simple, símbolos muy evidentes, poco elaborados, pero eficaces en ese contexto. En no pocas ocasiones se cruzaron esos mensajes electorales con la simbología de la antigua confederación, en una clara identificación del conservadurismo sureño con los republicanos y su propuesta.

En suma, la combinación del paulatino crecimiento de su colegio electoral con los procesos que subyacen bajo la aparente solidez republicana de este estado, algunos de cuyos síntomas manejados hasta aquí tienden a incrementar el interés que puede despertar en los políticos y en los estrategas de las campañas, a la vez que se presenta como un escenario claramente polarizado.

\section{El camino del Legislativo}

Las características del sistema político estadunidense, su estructura y dinámicas, se encuentran presentes también en Georgia, como es lógico, en tanto que componente de la Unión. Por tanto, se trata de un escenario en el que se expresan el personalismo de los procesos electorales, la ausencia de una disciplina partidista a nivel nacional, el déficit en la integración entre intereses locales y generales, la multiplicidad de grupos que intervienen en la vida política y el resto de los factores ya comentados. Como consecuencia, encontramos en ese territorio las divergencias y convergencias entre los distintos ámbitos del poder político formal e informal y entre los subprocesos electorales estudiados.

La hegemonía de los demócratas fue una realidad imperante durante largo tiempo también en las elecciones congresionales. Ya hemos visto cómo los electores 
georgianos se inclinaron de manera sostenida por ellos desde el siglo xIx hasta la segunda mitad del xx en los comicios presidenciales. Respecto del Legislativo encontramos un comportamiento más o menos similar durante mucho tiempo, con los republicanos excluidos de las sucesivas representaciones en el Congreso federal, insertándose dentro del bastión histórico del Partido Demócrata, asociado con las construcciones sociales que se aglutinaron en torno a la identidad sureña, la segregación racial y la tradición dixiecrat (demócratas conservadores sureños desde los tiempos de la Guerra de Secesión).

El reordenamiento del sistema político como parte de la gran crisis estructural sistémica de los años setenta, cuyos comienzos habría que buscar en la segunda mitad de los sesenta y que se extendió hasta los ochenta, tuvo expresiones de gran alcance e intensidad en el Peach State. Más allá de la crisis económica, muy estrechamente asociada con la ruptura del sistema Bretton Woods y los shocks petroleros, se registró una profunda crisis social que tuvo aquí uno de sus principales escenarios.

Probablemente lo más destacado en el territorio haya sido el movimiento por los derechos civiles, que fue muy poderoso en Atlanta, donde predicaba Martin Luther King Jr. Él experimentó una fuerte sinergia con los movimientos pacifistas, estudiantiles y contraculturales, y se integró con la crisis política de finales de los setenta (Hayden, 2009), para finalmente complementarse con las tendencias recesivas muy conocidas de la época; a lo anterior habría que agregar una crisis de los modelos teóricos en los distintos campos.

Todo conllevó un complejo proceso de realineamiento partidista de los electores y, evidentemente, una ruptura del monolítico predominio demócrata. Ya vimos cómo se producía esto en las elecciones presidenciales, veamos ahora su expresión en la rama legislativa.

En el cuadro 2 se aprecia claramente que, aunque los republicanos se insertaron en la bancada georgiana en el Congreso federal desde la década de los años sesenta, el predominio demócrata se mantuvo hasta comienzos de los noventa cuando, luego de un incremento significativo en 1992, los republicanos tomaron el control bruscamente en 1994. Además, a partir de las elecciones generales de 2004, los dos escaños en el Senado han estado en manos del Grand Old Party (GOP). Comparando con lo que habíamos observado respecto de las elecciones presidenciales, es evidente que en lugar de la transición, relativamente normal, aquí encontramos un cambio más tardío, que coincidió en el tiempo con la reorganización de los distritos congresionales a partir del aumento del número de representantes a la Cámara federal, posterior al censo de 1990, cuando se revirtió el estancamiento que había seguido a la reducción de 1930 (U.S. Census Bureau, 2010a). 
Cuadro 2

DESARROLLO HISTÓRICO

DE LA REPRESENTACIÓN DE GEORGIA EN EL CONGRESO FEDERAL

\section{Senado}

Año Demócratas

1946

1948

1950

1952

1954

1956

1958

1960

1962

1964

1966

1968

1970

1972

1974

1976

1978

1980

1982

1984

1986

1988

1990

1992

1994

1996

1998

2000

2002

2004

2006

2008

2010

2012

\section{Republicanos}

0

0

0

0

0

0

0

0

0

0

0

0

0

0

0

0

0

1

$$
1
$$$$
1
$$

0

0

0

\section{1}

1

\section{1}

1

0

1

2

2

2

2

2

\section{Cámara}

Demócratas

Republicanos

10

10

10

10

10

10

10

10

10

9

8

8

8

9

10

10

9

9

9

8

8

9

9

7

3

3

3

3

5

6

6

6

5

5

0

$$
0
$$$$
0
$$$$
0
$$$$
0
$$$$
0
$$$$
0
$$$$
0
$$$$
1
$$$$
2
$$$$
2
$$$$
2
$$$$
1
$$$$
0
$$$$
0
$$$$
1
$$$$
1
$$$$
1
$$$$
2
$$$$
2
$$$$
1
$$$$
1
$$$$
4
$$$$
8
$$$$
8
$$$$
8
$$$$
8
$$$$
8
$$$$
7
$$$$
7
$$$$
7
$$$$
8
$$$$
9
$$

Fuente: Elaboración propia con información del Senado y de la Cámara de Representantes federales $<w w w . s e n a t e . g o v>$, consultada el 15 de enero de 2013 y United States House of Representatives, en <www.house.gov>, consultada el 15 de enero de 2013. 
Dicho comportamiento es más evidente cuando se representa en una gráfica. Aquí graficamos el porcentaje de republicanos entre los representantes por Georgia en la Cámara federal, contra los años de las elecciones congresionales. Dado el número total de representantes, un máximo de catorce a partir de los resultados del censo de 2010, una variación pequeña en términos absolutos produce movimientos considerables en las proporciones. La gráfica 4 es muy explícita al respecto.

\section{Gráfica 4}

\section{REPUBLICANOS ENTRE LOS REPRESENTANTES POR GEORGIA}

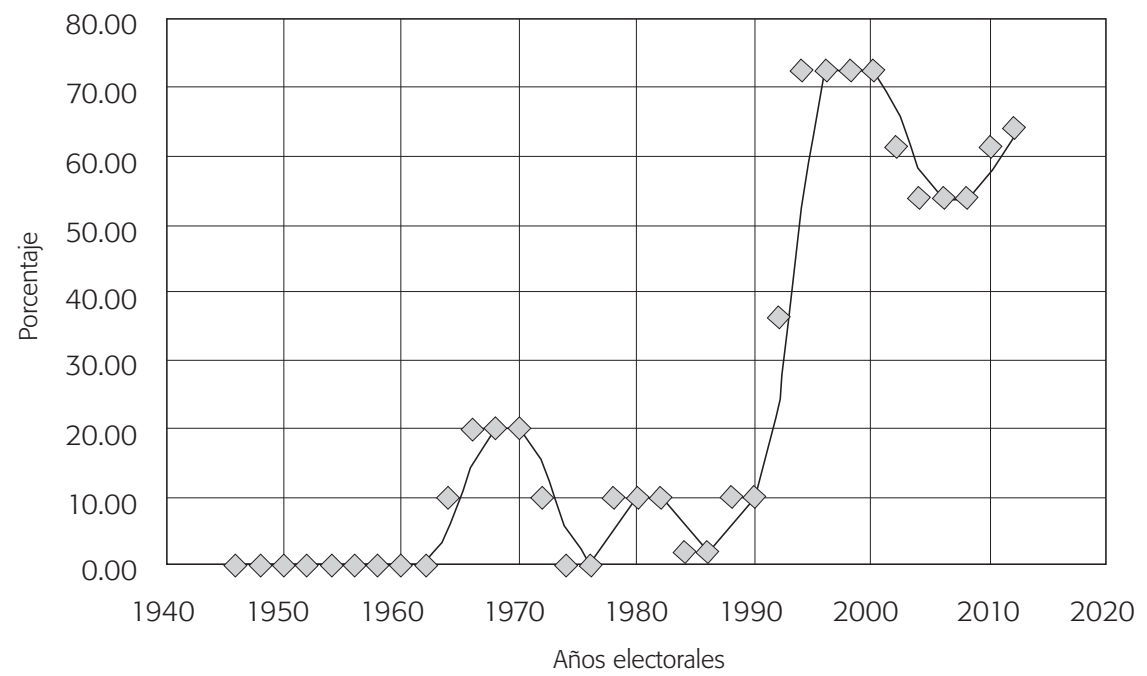

Fuente: Elaboración propia a partir de los datos de la United States House of Representatives, 2013.

Se aprecia una oscilación en niveles bajos desde los años sesenta hasta los noventa, con un brusco ascenso, para oscilar de nuevo en la década del 2000, pero ahora por encima del 50 por ciento. En el ajuste utilizamos una ecuación multiarmónica. Incluso las matemáticas demuestran las complejidades de este escenario, pues encontramos fragmentos de funciones muy diferentes en los distintos puntos de la gráfica 4. No se intenta extrapolar esta curva en busca de proyecciones a futuro, pues es sólo una ayuda visual, en tanto que quedan fuera numerosas variables, algunas no cuantificables.

Si comparamos con el comportamiento del estado en las elecciones presidenciales, nos encontraremos con que esta inversión en la composición de la representación georgiana en la Cámara federal coincide aproximadamente con el fin de la dilatada 
transición en aquel ámbito y el inicio de su Constitución en un solid state republicano. Por lo tanto, estamos encontrando evidencias de cómo se expresa, en términos numéricos, la relación entre los procesos de reordenamiento dentro del sistema electoral y más ampliamente dentro del sistema político. Parece haber una regularidad en el desfase temporal entre el subproceso presidencial y el Legislativo en cuanto al predominio partidista, lo cual complejiza las relaciones políticas en la entidad, por cómo se relacionan los distintos grupos de interés y los distintos sectores de las elites. La paulatina adecuación de todos ellos a los contextos cambiantes es lo que permite estabilizar nuevamente el sistema.

El universo de factores condicionantes de los procesos en el Peach State incluye una cantidad importante de combinaciones y escenarios individualizados que integran uno de los núcleos clave del funcionamiento del subsistema de gobierno. Teniendo en cuenta la distribución geográfica, Georgia forma parte del arco suroriental de estados que crecen en su peso específico dentro del sistema político por la mayor presencia en las instancias legislativas, además de por sus colegios electorales. Excepto Florida, cuyo elevado dinamismo es una constante histórica, los restantes componentes de ese arco (Virginia, Carolina del Norte, Carolina del Sur y Georgia) experimentaron una suave contracción en estos indicadores en las primeras décadas del siglo xx, para posteriormente experimentar una tendencia expansiva suave, aunque asíncrona (U.S. Census Bureau, 2010a).

Durante las elecciones de 2012, en este estado se produjeron quince contiendas del ámbito federal: la presidencial y las catorce de representantes. Se reprodujo el predominio republicano, algo esperado, impulsado por una reorganización de los distritos congresionales que los favoreció raíz del apportionment de 2010, como ha sucedido habitualmente en las últimas décadas en todo el Sur, pero la observación de otros indicadores genera dudas sobre la sostenibilidad a mediano y largo plazos del predominio republicano.

\section{LA COMPOSICIÓN DE LA POBLACIÓN}

Para justipreciar el alcance de los procesos que dominan el desarrollo del sistema político georgiano, conviene abordar la problemática demográfica. Por supuesto, ésta es parte del conjunto de tendencias que reconfiguran el escenario social y político estadunidense, pero sus peculiaridades contribuyen a la comprensión de campañas, resultados y repercusiones diversas del funcionamiento de los subsistemas electorales.

Lo que sobresale en este ámbito es la tendencia sostenida al rápido crecimiento de la población (a partir de los años ochenta), según los resultados oficiales de los cen- 
sos decenales, lo cual ha llevado también a un crecimiento relativo, al compararse con el comportamiento de otros estados y del promedio nacional. Por ejemplo, en 1980, Georgia ocupó, por el tamaño de su población, el decimotercer lugar a nivel nacional; en 1990, el undécimo, en 2000, el décimo, y en 2010, el noveno. Las tasas de crecimiento correspondientes a los periodos 1980-1990, 1990-2000 y 2000-2010 fueron del 18.6, el 26.4 y el 18.3 por ciento, respectivamente; es decir, se ubicaron siempre muy por encima del promedio del país, casi duplicándolo en los dos últimos censos (U.S. Census Bureau, 2012).

En el último decenio censado, la población total pasó de 8186453 a 9687 653, un crecimiento de un millón y medio, el cuarto mayor en términos absolutos, sólo superado por California, Texas y Florida. En términos relativos, la tasa incremental del estado fue la séptima mayor entre todos los sujetos federados, por encima incluso de las de Florida y California. Esto nos lleva a pensar en una tendencia sostenida que probablemente se extenderá en el futuro, colocando a Georgia en una posición cada vez más central en la distribución geográfica de la población estadunidense, es decir, es uno de los contribuyentes más importantes de la expansión demográfica del Sur, dentro del cual representó el 10.5 por ciento del aumento total del número de habitantes, sólo detrás de Texas y Florida (U.S. Census Bureau, 2010b). Se diría que esos tres territorios constituyen el núcleo demográfico del Sur, aunque sólo uno, justamente Georgia, sea parte del histórico corazón seccional, una de las antiguas colonias británicas y miembro fundador de la Unión.

Es muy importante en ese último decenio el aumento total de votantes efectivos en las elecciones presidenciales (descontando la de 2012), pues quedan fuera del decenio, además de que en éstas se produjo una leve disminución (fue de un 51.1 por ciento), tomando como referente las elecciones del año 2000. Si incluyéramos las de 2012, la tasa sería del 49.4 por ciento. En los dos decenios precedentes fue del 11.9 por ciento en 1990-2000 y del 13.3 por ciento en 1980-1990 (The American Presidency Project, 2012). Estas comparaciones no son exactas, pues los ciclos electorales no se corresponden con los censales; además, estamos hablando de participación efectiva, no de cantidad de ciudadanos elegibles como votantes $u$ otro de los posibles indicadores por observar.

De cualquier manera, se evidencia que en el último decenio el incremento acumulado de la población tuvo un brusco crecimiento de la población votante real, es decir, los niveles de politización visible se elevaron más en ese periodo, en comparación con el relativo retraso de los decenios anteriores.

Por supuesto que en este tema influyen numerosos factores (incluyendo los efectos desmovilizadores de las características del sistema), como las diferencias entre las distintas candidaturas, las restricciones al derecho al voto que se interponen en el cami- 
no de diversas comunidades, entre otros. Un papel significativo lo representan los ritmos de arribo a la edad electoral de los jóvenes provenientes de las minorías de más rápido crecimiento, así como los índices de naturalización de grupos de inmigrantes.

El cuadro resulta más elocuente si consideramos la distribución de esa población. Como es normal, su densidad no es homogénea, pero el mapa nos muestra muy notables desniveles en todos los aspectos. Respecto de los totales y la densidad superficial, encontramos en el Centro-Norte una zona de gran concentración de habitantes, sobre todo en condados como Fulton y DeKalb. En la faja costera del estado se hallan otros territorios que se sitúan por detrás de éstos, pero incluso en niveles relativamente importantes, de acuerdo con el comportamiento general en el estado. En el extremo inferior se sitúan vastas zonas del Sur, el Centro y el Noreste, áreas fundamentalmente rurales. La geografía del crecimiento demográfico es similar, con tasas muy elevadas en las mismas zonas descritas como de mayor densidad poblacional, en las que encontramos, en algunas áreas, cifras en torno o superiores al 50 por ciento, es decir, ritmos muy elevados. En las zonas rurales y micropolitanas de menor densidad se registran incluso decrecimientos, con ritmos notables en zonas cercanas a la frontera con Alabama (U.S. Census Bureau, 2010b).

Recordemos que, superpuesta con esos populosos condados del Centro-Norte, se encuentra el área metropolitana de Atlanta-Sandy Springs-Marietta. Ésta ocupaba, en 2010, el noveno puesto a nivel nacional por su total de habitantes, que según el censo de ese año sumaban 5268 860, lo cual equivalía al 54.4 por ciento del total de la entidad. Eso con una tasa de crecimiento intercensal del 24.0 por ciento, la segunda más alta entre la decena de sus homólogas más populosas, sólo superada por Houston-Sugar Land-Baytown en Texas (U.S. Census Bureau, 2010b).

Evidentemente, este centro de gravedad demográfico es el principal motor del crecimiento estatal y un factor de gran importancia por considerar en las dinámicas sociales, políticas y económicas del territorio.

En su interior está la ciudad de Atlanta, mencionada varias veces en este trabajo, que es una especie de capital del Sur, pues ahí se sitúan las sedes de numerosas instituciones federales, desde las cuales se dirige el trabajo de las oficinas distribuidas por la región. Es, además, un gran centro financiero, donde se concentran filiales y casas matrices de importantes corporaciones bancarias, aseguradoras y de otros tipos; sin embargo, la ciudad como tal ha visto detenida su expansión territorial, a pesar de la continuidad de su núcleo urbano en zonas administrativamente separadas, por la negativa de las instancias gubernamentales del estado a permitir la incorporación de esas áreas, como, por ejemplo, la ciudad de Decateur, en la práctica un distrito del casco urbano de Atlanta. Las razones para esa posición se hallan en los factores técnicos y legales de distinto tipo, pero también en la presencia de una fuerte comunidad 
de color, la cual ha controlado las principales instancias de gobierno local durante los ciclos electorales más recientes, y que las autoridades estatales y las comunidades blancas circundantes no quieren que incremente su radio de acción política.

Esto nos lleva a considerar la composición de la población georgiana. Desde el punto de vista de las categorías raciales utilizadas oficialmente por la Oficina del Censo de Estados Unidos, la mayor parte de la población es blanca, pero existe una numerosa población negra. Por su número absoluto (2 950 435), en 2010 era la cuarta del país con el 7.3 por ciento del total nacional, sólo superada por las de Nueva York, Florida y Texas, en ese orden, todas muy próximas, en un rango de unas ciento veinte mil personas de diferencia. En términos porcentuales era también la cuarta (el 30.5 por ciento), superada en este aspecto por las del Distrito de Columbia, Misisipi y Luisiana, todos territorios con mucha menos población. De hecho, los afroamericanos representan una proporción muy elevada de la población en toda la geografía del estado, excepto en su extremo norte, en los condados de las zonas montañosas, donde eran menos del 5 por ciento en 2010 (U.S. Census Bureau, 2010d). Éste es un factor muy importante, pues desde los sesenta los electores afroamericanos han apoyado abrumadoramente a los candidatos presidenciales demócratas. Por ejemplo, sondeos a boca de urna de Gallup muestran que entre 2000 y 2008 los votantes afroamericanos apoyaron a los candidatos del Partido Demócrata en un rango entre el 91 y el 99 por ciento (Gallup, 2012).

Aún más importante es que esa comunidad tuvo un crecimiento del 25.6 por ciento en el decenio 2000-2010, muy por encima del ya elevado del estado, lo que la convirtió en el principal motor del crecimiento de la población, al aportar el 40 por ciento de los nuevos habitantes. Este incremento se concentró en los condados del Centro-Norte, los más populosos (U.S. Census Bureau, 2010d). Los asiáticos también tuvieron un gran incremento, aunque su número es menor (314 467); ellos aumentaron en un 81.6 por ciento en el decenio, aportando el 9.4 por ciento del aumento global. Si comparamos esta última cifra con lo que ellos representan en el total (un 3.2 por ciento), se evidencia que su impacto sobre la dinámica demográfica estatal es superior a su importancia numérica en términos absolutos. Además, su incremento más rápido se produce en los mismos condados del Centro-Norte que hemos señalada repetidamente (U.S. Census Bureau, 2010c).

La población blanca, por su parte (5 423 920), aunque aumentó, lo hizo en un 5.6 por ciento, muy por debajo de las minorías. Únicamente aportó el 19.0 por ciento del incremento total, a pesar de ser la mayoría de la población (U.S. Census Bureau, 2010f). El resto del aumento fue aportado por otros grupos, sobre todos por los mestizos (o combinados), como los llaman las instituciones oficiales de Estados Unidos. 
De manera que un rápido vistazo a las estadísticas nos muestra una composición racial con dos núcleos dominantes, blancos y negros, pero en medio de un proceso de transformación que abre importantes espacios para otras comunidades, de acuerdo con el mayor o menor dinamismo que presenten. Es previsible que, en un futuro no muy lejano, los blancos dejen de ser la mayoría -posiblemente en 2020, casi seguro en 2030-, lo cual llevaría tempranamente a Georgia a la situación de una serie de minorías sin una comunidad con la mayoría absoluta. Aunque, de sostener ritmos parecidos a los actuales, la comunidad negra sería candidata a ese puesto, pues en el Peach State su tasa de crecimiento es casi dos veces y media mayor que la que tiene a nivel nacional. Ésta es una de las tendencias que han incidido más fuertemente en la evolución del sistema político estatal durante las décadas posteriores a la revolución conservadora de los ochenta.

Y el panorama se vuelve más complejo si incluimos a los hispanos. Aquí utilizamos la denominación hispanos de acuerdo con la categoría censal homónima empleada por la Oficina del Censo de Estados Unidos, la cual incluye a latinoamericanos e ibéricos. Es diferente de las categorías raciales, como negros, blancos y asiáticos, por ser esta misma multirracial. En los informes de las instituciones estadunidenses se utiliza de forma intercambiable con latinos. Georgia no figura entre los estados con mayor presencia latina, pues en 2010 ocupaba el puesto veintidós en el porcentaje de la población total (un 8.8 por ciento), aunque era el noveno por su volumen total (853 689). Claro, esto último se corresponde con la importancia numérica de la población general, también en el noveno puesto, pero con el crecimiento más rápido de todos los registrados entre los grupos étnicos, con un 96.1 por ciento en el decenio, lo cual aportó el 30.0 por ciento del aumento total, o sea, mucho más que la parte de la población que representa (U.S. Census Bureau, 2010e).

Esto significa que los latinos han adquirido un peso creciente dentro de la población total de Georgia, que ha aumentado su importancia política sin llegar a ser un factor decisivo. Esta influencia política depende de muchos factores, entre los que destaca el ritmo con el que los hispanos adquieren la ciudadanía y se registran como electores, lo cual es un proceso más lento que el simple crecimiento. Entre los inmigrantes asentados en esa entidad, en 2009 estaba naturalizado el 34.0 por ciento, equivalente al 3.2 por ciento de la población total de ese año (U.S. Census Bureau, 2009).

No contamos con datos sobre el comportamiento electoral de los hispanos en Georgia, pues no se encuentra entre los estados donde se realizó el sondeo a boca de urna del Pew Hispanic Center (2012), principal fuente de información de la que se dispuso para este escrito; no obstante, se pueden hacer algunas inferencias a partir de otros datos. En este territorio, la mayor comunidad latina la forman las personas de origen mexicano, más de un 60 por ciento. A su vez, ellos eran el 63.0 por ciento del total 
nacional en 2010 (U.S. Census Bureau, 2010e); ello, recordando que los hispanos han favorecido durante décadas a los candidatos presidenciales demócratas. Entre 1980 y 2012, el porcentaje de su voto por los demócratas se movió entre el 56 y el 72 por ciento, respectivamente, mientras que los republicanos recibieron entre el 21 y el 40 por ciento. En 2012, estas cifras fueron el 71 y el 27 por ciento, respectivamente (Pew Hispanic Center, 2012).

Considerando esto, así como el tipo de escenario en el que se desenvuelven, asumimos que su comportamiento se aproxima al promedio del país. Extrapolando las tendencias, esto significa que representarían algo más del 5 por ciento del electorado, con una preferencia por los demócratas de casi el 70 por ciento en la elección presidencial de 2012. Esto daría una contribución neta al presidente demócrata de al menos dos puntos. A todas luces fue una cifra aún insuficiente para definir, en un estado como Georgia, pero su tendencia al crecimiento encierra potenciales muy importantes.

Un aspecto en el que los hispanos difieren del resto de las comunidades étnicas del estado es que la distribución territorial de su crecimiento es más homogénea. Sólo se registran bajas tasas de incremento en algunos condados del Suroeste y unos pocos del Este. En el Norte, el Oeste, el Centro, el Sur y el Noreste las tasas son, en casi todas partes, superiores al 50 por ciento (Pew Hispanic Center, 2012). Esto significa que su presencia está acrecentándose no sólo en los principales núcleos urbanos, sino también en las zonas rurales. A más largo plazo, éste será un factor que contribuya a un reacomodo en la configuración de fuerzas en espacios locales habitualmente controlados por los sectores más conservadores, pero esto sería un proceso mucho más lento, condicionado por los niveles de naturalización y registro, así como por el trazado de los distritos congresionales.

También conviene recordar que el Peach State, como parte del Sun Belt, recibe un flujo considerable de inmigrantes nacionales. Según el censo de 2010, se registraba un 33.9 por ciento de personas nacidas en otros estados residiendo en Georgia. Ésta no es una de las proporciones más altas del país, donde ocupa el vigésimo puesto, pero es una masa de población importante, una parte de ésta (sin precisar), proveniente del Norte. Este tema requiere mayor profundización, considerando las diferencias entre las distintas regiones.

\section{Conclusiones}

La función de Georgia en el sistema político estadunidense, concretamente en el ámbito electoral, ha evolucionado desde ser un sólido bastión del Partido Demócrata, hasta convertirse en un punto de apoyo para el Partido Republicano. Esto se ha pro- 
ducido de manera diferente en los tres principales subprocesos que conforman los procesos electorales a nivel federal. Ello ha coincidido con un lento aumento de su peso relativo dentro del sistema, por el incremento del total de votos electorales y congresistas que posee.

En los comicios presidenciales se produjo una lenta y compleja transición que abarcó dos décadas (de los sesenta a los ochenta). En las elecciones para la Cámara de Representantes hubo un brusco cambio en la composición de la bancada georgiana, con una abrupta transferencia al control republicano, pero en fecha más tardía (en los noventa). En el Senado, si bien la presencia republicana inició en los ochenta, se convirtieron en dominantes, es decir, ocuparon los dos puestos correspondientes al estado a partir de 2004 .

También se aprecia que los márgenes con los cuales se imponen los ganadores en las elecciones presidenciales a nivel estatal han tendido a reducirse notablemente a partir de los noventa, generando una situación de relativo equilibrio. Esto coincide parcialmente con la relativa estabilización de la proporción de republicanos y demócratas entre los representantes del estado en el Congreso federal, en un rango de variaciones relativamente reducido en niveles favorables a los primeros.

Esto demuestra, por un lado, que el electorado estadunidense tiende a separar esos procesos, de acuerdo con sus preferencias por figuras individuales en interacción con marcos políticos, sociales y económicos más generales. Por otra parte, se demuestra que los factores que han incidido en ambos procesos son diferentes, actuando con ritmos también diferentes. Aquí entran, en primer lugar, los cambios en las proyecciones y la actuación de los partidos, y los vínculos con los intereses seccionales, particularmente a partir de 1964, y la dinámica demográfica en todas sus dimensiones, con sus efectos sobre la población electoral. La interacción entre esos factores, dentro de los marcos generales de la organización del sistema político estadunidense, alcanzó un punto crítico entre 1980 y 1992, periodo en el que se completó la transformación.

Muy importante entre las tendencias de las últimas décadas ha sido la evolución de la composición demográfica de la población de Georgia. Éste es un territorio donde la población negra siempre fue relevante; sin embargo, los ritmos acelerados de crecimiento que esa comunidad experimentó en las décadas más recientes, aunados a las bajas tasas incrementales de los blancos no hispanos (mayoría histórica), han ido variando esa correlación. Otras minorías, particularmente asiáticos e hispanos, han aumentado muy rápidamente, por lo que la composición y equilibrio de fuerzas a nivel social se ha vuelto más compleja.

Las sólidas raíces sureñas y las tendencias sociodemográficas y étnicas de la población entran en una interacción compleja sumamente interesante. Si bien hasta las elecciones generales de 2012 los efectos de ese desarrollo sobre el sistema político 
-y en particular sobre los procesos electorales- eran limitados, se aprecian algunos síntomas de corrientes subyacentes que apuntan a cambios en el futuro.

Los resultados específicos del último proceso en ese escenario están, por ende, condicionados por esos factores, además de por las dinámicas de alcance nacional de distinto tipo y nivel. En este escenario, se han expresado con fuerza varias de las tendencias más importantes presentes en todo el sur de Estados Unidos, y más ampliamente a nivel nacional. Por lo tanto, es un escenario muy activo de los procesos políticos y sociales contemporáneos en desarrollo en ese país.

\section{FUENTES}

American Presidency Project, the

2012 "The American Presidency Project", en <www.presidency.ucsb.edu>, consultada el 28 de agosto.

Black, EARl y Merle Black

2002 The Rise of Southern Republicans, Cambridge, The Belknap Press of Harvard University Press.

Burnham, WALTER DeAN

1970 Critical Elections and the Mainsprings of American Politics, Nueva York, W. W. Norton.

ChHibber, Pradeep y Ken Kollman

2004 The Formation of National Party System. Federalism and Party Competition in Canada, Great Britain, India, and the United States, Princeton, Princeton University Press.

FONER, ERIC

2011 The Fiery Trial. Abraham Lincoln and America Slavery, Nueva York, W. W. Norton.

Franco Hijuelos, Claudia, Rafael Fernández de Castro

y FRANCISCO LORENZO, comps.

1996 ¿Qué son los Estados Unidos?, México, McGraw-Hill.

Gallup

2012 “U.S. Presidential Election Center", en <www.gallup.com>, consultada el 3 de septiembre. 
Genovese, Eugene D.

1989 The Political Economy of Slavery. Studies in the Economy and Society of Slave South, Middletown, Wesleyan University Press.

Giddens, ANTHONY

2003 La tercera vía. La renovación de la socialdemocracia, Madrid, Taurus.

HALL, KeRMit L., ed.

1992 Major Problems in American Constitutional History, Lexington, Heath.

Hamilton, Alexander, James Madison y John Jay

1961 The Federalist Papers, Nueva York, New American Library.

HASDAY, JUdY L.

2007 The Civil Rights Act of 1964. An End to Racial Segregation, Nueva York, Chelsea House.

HAYDEN, TOM

2009 The Long Sixties. From 1960 to Barack Obama, Boulder, Paradigm.

Mason, MatheW

2006 Slavery and Politics in Early American Republic, Chapel Hill, The University of North Carolina Press.

Mills, Charles Wright

1957 The Power Elite, Nueva York, Oxford University Press.

Morrison, Samuel Eliot, Henry Steele Commager y William E. Leuchtenburg

1987 Breve historia de los Estados Unidos, México, FCE.

Pew Hispanic Center

2012 "Latino Voters in the 2012 Election", en <www.pewhispanic.org >, consultada el 7 de noviembre.

SCHAFER, BYron E. y RichARD JOHNSTON

2006 The End of Southern Exceptionalism. Class, Race and Partisan Change in the Postwar Era, Cambridge, Harvard University Press. 


\section{SCHLESINGER JR., ArTHUR}

1990 Los ciclos de la historia americana, Buenos Aires, REI.

\section{United States Census Bureau}

2012 "Statiscal Abstract 2012", en <www.census.gov>, consultada el 20 de junio.

2011 "US. Code", en <http: / / www.gpo.gov / fdsys / browse / collectionUScode.act ion? collectionCode=USCODE\&searchPath=Title+12\&oldPath=\&isCollapse $\mathrm{d}=$ true\&selected YearFrom=2011\&ycord $=570>$, consultada el 6 de mayo de 2012.

2010a “Congressional Apportionment. Census 2010", en <www.census.gov>, consultada el 14 de agosto de 2012.

2010b “Population Distribution and Change. Census 2010", en <www.census.gov>, consultada el 20 de junio de 2012.

2010c “The Asian Population: 2010", en <www.census.gov>, consultada el 20 de junio de 2012.

2010d “The Black Population: 2010", en <www.census.gov>, consultada el 20 de junio de 2012.

2010e “The Hispanic Population: 2010", en <www.census.gov>, consultada el 20 de junio de 2012.

2010f “The White Population: 2010", en <www.census.gov>, consultada el 20 de junio de 2012.

2009 "Nativity Status and Citizenship in the United States: 2009", en <www.census. gov>, consultada el 23 de mayo de 2013.

United States House of Representatives

2013 "United States House of Representatives", en <www.house.gov>, consultada el 15 de enero de 2013.

\section{United States Senate}

2013 "United States Senate", en <www.senate.gov>, consultada el 15 de enero de 2013.

WEBER, MAX

1971 Economía y sociedad, La Habana, Ciencias Sociales. 